\title{
Lo narrado en imágenes (o las imágenes narradas). Ficciones, pruebas, trazos y fotografías en las publicaciones de los escritores en blogs
}

\section{Vigna, Diego}

Resumen:

Las relaciones entre la producción escrita y el universo virtual que brotaron de la popularización de los soportes y formatos digitales llevaron a pensar en la aparición de ciertos fenómenos que ampliaron las tensiones entre la cultura impresa y la llamada cultura digital. En el contexto de la explosión informática, el formato blog fue incorporado por escritores para explorar nuevas facetas de trabajo y vinculación.

Aquí me ocupo de una de las facetas que han desarrollado: la mixtura entre texto, imagen, sonido y audio en el trabajo, aun cuando ese cruce no había sido concebido antes como algo cotidiano en las rutinas de

Cuadernos del Centro de Estudios de Diseño y Comunicación Nº 61

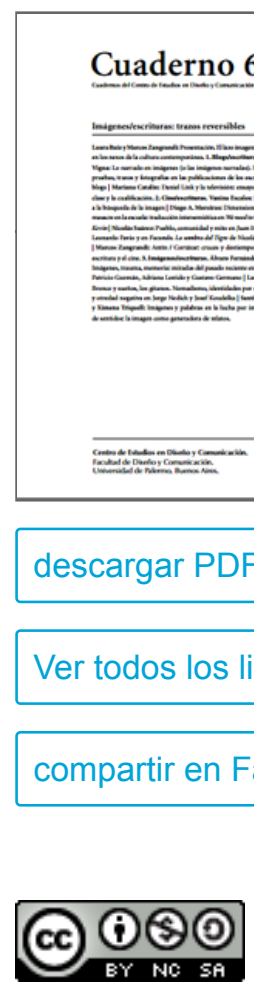

Esta obra está bajo una Licencia Creative Commons Atribución-NoComercialCompartirlgual 4.0 Internacional

publicaciones, fueran de ficción o de textos marginales. El análisis de los blogs de escritores ha significado un ejemplo más de la marca de época: voces que fueron, en realidad, texto en pantalla y, por tanto, la palabra que fue y es traducida en imagen. Las imágenes forman parte de los textos de los autores, de sus tramas, de sus planes, y el desarrollo de la experimentación entre el lenguaje verbal y el audiovisual, se hace cada vez más presente en sus cruces e influencias.

Palabras clave: blogs de escritores - cultura impresa - cultura digital - producción escrita - ambiente hipermedial.

$\left(^{*}\right)$ Licenciado en Comunicación Social y Doctor en Estudios Sociales de América Latina, ambos por la Universidad Nacional de Córdoba. Becario posdoctoral del Centro de Investigaciones y Estudios sobre Cultura y Sociedad (CONICET) e investigador del Centro de Estudios Avanzados (UNC). Coordinador del programa de investigación "Nuevos frutos de las Indias occidentales: estudios de la cultura latinoamericana" (UNC). 
Pasaron muchísimas cosas durante la última década, y la producción cultural y artística no ha escapado al momento bisagra que brotó en la dinámica social con una intensidad inusitada, común a casi todas las disciplinas. En medio de un clima de época donde las capacidades creativas y el ambiente técnico conviven en plena tensión y exigen repensar la concepción instrumental de las acciones de los sujetos (Ellul, 1990 [1960]; Mumford, 1960; Schmucler, 1997) en todos los campos, propongo un acercamiento a esa bisagra que significó, para la producción literaria, la irrupción de los formatos de publicación web y su asimilación por parte de autores y lectores en la década comprendida entre 2002 y 2012. Las relaciones entre la producción escrita y el universo virtual que brotaron de la popularización de los soportes y formatos digitales llevaron a pensar (para algunos con prudencia, para otros casi forzando una revolución) en la aparición de ciertos fenómenos, desde el cambio de siglo, que ampliaron las tensiones entre la cultura impresa y la llamada cultura digital. En ese contexto de explosión informática, y de medios de información hipermediales, el formato blog fue incorporado por escritores argentinos de distintas trayectorias y generaciones para explorar nuevas facetas de trabajo y de vinculación, dando lugar, en su momento, a un horizonte de expectativas: incluso hasta hoy, con el uso extendido de las redes sociales, ningún otro formato de publicación digital ha participado con tal intensidad del trabajo escriturario, en el seno del campo.

En la revisión de prácticas, tanto en lo que respecta a la producción de obras y pensamientos como a los modos de interacción entre autores y lectores, surgieron preguntas: cómo se insertó el blog en el trabajo de los escritores; qué cambios marcó su aparición en relación a las "formas" impresas, protagonistas desde el siglo pasado en la difusión y legitimación de autores y de obras. El objeto de mis preguntas estuvo puesto en el trabajo de escritores consagrados o en vías de consagración, es decir, autores con una obra publicada en soporte impreso que además han tenido presencia en medios dedicados a la producción crítica y literaria. Y, por supuesto, que han administrado (o administran) espacios personales en la llamada "blogosfera", con una actualización periódica de sus contenidos.

El blog fue ofrecido al consumo público como un diario personal de apuntes o bitácora personal, diferenciado de los formatos web que dieron forma y visibilidad a Internet (sobre todo, las páginas web). De hecho, su denominación original (weblog) remitía directamente a la idea de bitácora de navegación (un juego respecto de la "navegación en la web") por sus cualidades específicas: entradas, posts o publicaciones fragmentadas y ordenadas en forma cronológica inversa (la más reciente en primer orden) que pueden ser comentadas por los lectores; enlaces que permiten acceder a contenidos ajenos al espacio; vínculos inmediatos a otros blogs y sitios de la web; organización semántica de los contenidos a partir de etiquetas (Orihuela, 2004; Fumero, 2005; Wrede, 2005; Doueihi, 2010). Por esas características distintivas, el formato blog tomó relieve en el universo de las publicaciones digitales por su doble cualidad personal y relacional (Wrede, 2005). Desde sus particularidades, la relación que originalmente tuvo el formato con las instituciones de la literatura heredada y los formatos de publicación impresos fue híbrida, y difusa: el blog se alejaba del libro, aunque también, a primera vista, de las revistas y los suplementos culturales, porque aún en su búsqueda relacional, y en su capacidad de remitir a otros contenidos y a otros espacios y autores, apuntaba la discusión hacia la autorreferencialidad y hacia las formas biográficas (Arfuch, 2002, p. 14) pero, también, a la exposición de la intimidad.

La paradoja que sostuvo la novedad apuntó a una nueva experiencia de escritura y difusión, íntima y espectacular: inscribir la voz propia y la intimidad para ser mostrada y, por causa de esa maniobra, revelar recién a partir de esa mostración sus posibles sentidos y derivaciones, la naturaleza de lo puesto en relieve. Desde el punto de vista de la recepción, lo que se presentaba como novedoso, por lo menos frente a las experiencias y 
producciones previas dedicadas a pensar la voz íntima objetivada en la palabra escrita, fue una de las banderas de los formatos web: la recepción inmediata, y la posible simultaneidad en la inscripción de las voces entre autores y lectores.

Aquí me ocuparé, específicamente, de una de las facetas que los escritores han desarrollado en el uso de sus espacios, quizás la más novedosa dentro del carácter hipermedial del formato: la mixtura entre texto, imagen, sonido y audio en el trabajo de los autores, aun cuando ese cruce no había sido concebido antes como algo "cotidiano" en las rutinas de publicaciones, fueran de ficción o de textos marginales (Casarin, 2007). Teniendo en cuenta que uno de los fenómenos más discutidos en torno a la publicación en formatos digitales fue la exaltación de una ilusión oral, el análisis de los blogs de escritores (sobre todo, durante los años de mayores publicaciones: 2004 a 2010) ha significado un ejemplo más de la marca de época: que esas voces fueron, en realidad, texto en pantalla y, por tanto, que la palabra fue (es) traducida en imagen. Y que las imágenes han formado parte (cada vez con mayor intensidad) de los textos de los autores, de sus tramas, de sus planes: el desarrollo de la experimentación entre el lenguaje verbal y el audiovisual, sus cruces e influencias.

Los escritores que con mayor periodicidad utilizaron el blog para encauzar distintas prácticas (de experimentación prosaica y poética, de promoción de obra, de archivo de textos, de "relajación" en términos de las exigencias del campo literario, apelando a una escritura liviana, informal) hicieron de la publicación de textos un diálogo con la publicación y el trabajo con imágenes, videos y audios. A partir de la consolidación de estas rutinas, la tarea de los escritores se volvió mucho más visual y orquestada. Un recorrido por los autores que usaron el blog para ensayar variantes escriturarias, y expresivas, permite reflexionar sobre el hipermedio, que discutió ciertas estéticas de producción y, por tanto, ciertas modas.

Analizaré cuatros aristas: textos que nacieron en pantalla para luego ser impresos; el trabajo de escritores con fotografías; experimentos narrativos a partir de imágenes y la publicación de borradores escaneados.

Pero antes, un repaso para ubicar la cuestión digital en la tradición de los soportes impresos.

La información en los soportes digitales: pantallas y textos

Como señaló Aguirre Romero (1997), la digitalización es una forma de almacenamiento de información a partir de un proceso mediante el cual distintos tipos de informaciones se reducen a una "forma común". Para entenderlo se puede partir del sistema de escritura alfabética: si la escritura común es una forma de establecimiento del sonido a una forma gráfica, convenida y, por tanto, descifrada como equivalente, el sistema digital permitió reducir a un lenguaje común (binario y numeral) elementos de distinta naturaleza, como la palabra, el sonido, la imagen y el video (Aguirre Romero, 1997). De ese modo, permitió reunir datos que antes necesitaban de soportes separados: el libro heredado, tal como lo conocemos, no puede incluir palabras y sonidos o videos. Esa convergencia renombró las funcionalidades en la producción y recepción de contenidos, y, en consecuencia, nuevas valoraciones sociales y culturales.

La digitalización puso en evidencia la separación entre la información y el soporte. Frente al libro como soporte y contenido, los soportes digitales, comunicados al lector-consumidor a través de pantallas, se definieron por el carácter energético, virtual, de la información, en oposición al carácter material de los soportes tradicionales (Aguirre Romero, 1997). Además, los contenidos publicados en un medio digital pueden ser transmitidos y 
difundidos a través de otros soportes gracias a las redes de información, y recibidos desde múltiples puntos; eso es lo que me incumbe para destacar el poder de las redes en las nuevas rutinas de publicación y visibilización de autores.

Para Roger Chartier, la "consecuencia ineluctable de la civilización de la pantalla, del triunfo de las imágenes y de la comunicación electrónica" (2001) ha puesto en tensión el avance del texto electrónico. Chartier ha destacado que las pantallas, hoy tan comunes para la fracciones medias y altas de las sociedades occidentales, marcaron el cuestionamiento de la noción de libro a partir de la textualidad electrónica. Pero ¿de dónde nace ese cuestionamiento? De los cambios fundamentales a nivel de los soportes, y, por tanto, a nivel cultural.

En la cultura impresa, una percepción inmediata asocia un tipo de objeto, una clase de textos y de usos particulares. El orden de los discursos se establece así a partir de la materialidad propia de sus soportes: la carta, el periódico, la revista, el libro, el archivo, etc. No es lo mismo en el mundo numérico donde todos los textos, cualesquiera sean, se dan para leer en un mismo soporte (la pantalla del ordenador) y en las mismas formas (generalmente las decididas por el lector). Así, se crea un continuum que no diferencia más los distintos géneros o repertorios textuales (...). El efecto no está sobre la definición misma de "libro" tal como lo entendemos nosotros, a la vez como un objeto específico, diferente de otros soportes de lo escrito, y como una obra donde la coherencia resulta de una intención intelectual o estética. La técnica numérica bascula ese modo de identificación del libro desde que ellos se convierten en textos móviles, maleables, abiertos y de formas casi idénticas a todas las producciones escritas: correo electrónico, sitios de Internet, libros, etc.

(Chartier, 2001) Además, por la naturaleza de las pantallas y de las funciones del texto electrónico, no lineal, susceptible de vincularse con imágenes, audio, video y otros textos y formatos en el mismo soporte, Chartier marcó una consecuente transformación epistemológica: el autor puede desarrollar una argumentación según una lógica no necesariamente lineal, sino abierta y relacional, donde el lector puede consultar otros documentos (archivos, imágenes, palabras, música) (2001). Y a esa transformación se sumó el papel decisivo de las redes.

Fernando Colla ha mencionado la tendencia delineada en la última década que privilegió (y lo hace cada vez más) los accesos a contenidos instalados en la web respecto de la adquisición de archivos (hoy cualquier libro electrónico o ebook no es otra cosa que un documento o archivo, codificado según un formato específico). Como tradujo Colla, hace ya cuatro años, del Informe sobre el libro digital en Francia (2008), la evolución de Internet, sobre todo a partir de la aparición de la banda ancha de transmisión de datos, reforzó la importancia del acceso, y en la actualidad los flujos son más importantes que el stock, y los usuarios se van desinteresando un poco de los discos duros de almacenamiento prefiriendo el acceso online a los contenidos digitales (Colla, 2010, pp. 423424).

Lo cierto es que la digitalización de todo lenguaje inauguró la posibilidad de recuperar información antes restringida a los soportes impresos; como también consideró la relativización sobre el destino de todos los libros, remarcando que no todos los contenidos se ven afectados de la misma manera. Y, también, destacó las complicaciones de pensar los nuevos productos culturales desde la analogía con el libro, algo que se nutre como problemática permanente en el seno de la producción cultural y artística.

Sin embargo, desde el abordaje estrictamente "literario", hay una identificación demasiado grande, en todo sentido, con el objeto libro, por ser "el soporte que permitió su desarrollo social" (Aguirre Romero, 1997). Sobre 
esa identificación, Chartier discutió su esencia: afirmó que los autores no escriben libros, sino "textos que se transforman en objetos escritos, manuscritos, grabados, impresos" (1994, p. 30). A partir de esto, Aguirre Romero sugirió no ocuparse de cómo afectarán las nuevas "formas digitales" a la literatura sino buscar, en cambio, sus nuevos nombres y categorías. Milad Doueihi, por su parte, afirmó que la "migración digital", pese al éxito reconocido en ciertos ámbitos, no ha dejado de estar asociada a los modelos impresos y a sus valores sociales; pero eso no implica que no haya producido formas propias de autoridad digitales (Doueihi, 2010, p. 120). Norma Carricaburo, afinando el análisis hacia la ficción en formatos hipermediales, dijo que la fusión de lenguajes ha ayudado a los lectores a organizar nuevos modos de lectura, a completar fragmentos, a sumar interpretaciones a los textos (2011, p. 64).

En relación con este trabajo, la indagación ha resaltado que los escritores que publican en papel y que en paralelo han mantenido blogs no han dejado nunca de escribir libros: más allá del formato, o de lo que permite visibilizar la obra, o lo que encauza los ensayos de sus "maniobras" estéticas, los escritores siguen detrás de los libros. Lo que no quiere decir (otra vez) que hayan restringido el valor de sus experimentaciones a ese destino final, signo de la tradición. Carricaburo (2011) afirmó que hoy la literatura se ve compelida a adecuarse a lectores acostumbrados a la lectura de la imagen; esta idea puede sonar un tanto tramposa pensando en los productores. No parece muy certera la idea de que los escritores intentan adecuar sus proyectos narrativos a los "lectores ávidos de imagen". Muchas veces han sido los mismos autores, permeados por ciertas posibilidades que pusieron en relieve estos medios, lo que han decidido ensayar y probar nuevos registros, quizás pensando más en el devenir de sus procesos creativos. Esto es lo que intento repasar aquí, esos ensayos de registros: expondré variantes notables de la prueba y la convivencia de la práctica narrativa con otros lenguajes, a partir de las posibilidades del formato.

Textos de la pantalla al libro

En el primer escalón que propongo en esta convivencia entre escritura y pantalla, destaco algunos autores que han experimentado con textos producidos originalmente para el formato blog y que, luego, decantaron en libros. Las pruebas parecieron dirigirse a un intento de objetivación inmediata de lo escrito, quizás adecuando el impulso primigenio del asiento de la experiencia (antes restringido a la idea de borrador) a uno de los rasgos inherentes al formato, que fue el de producir (publicar) y, poco tiempo después, poder recibir la respuesta de los lectores. El proceso estuvo claramente implicado dentro de la noción de diario, es decir, dentro de las pautas que el formato fomentaba; sin embargo, el hecho de ofrecer relatos para ser publicados de inmediato permitió que los autores utilizaran las pantallas para establecer una suerte de primer momento en la experiencia de publicación que, con la sedimentación posterior, terminó desnudando el destino quizás implícito: hacer de cada fragmento una parte o "capítulo" de libro.

Juan Diego Incardona1 suscribió a la idea de diario o bitácora desarrollando una narrativa vivencial (Arfuch, 2002) donde se mezclaban su trabajo (la venta ambulante), el tránsito entre la ciudad de Buenos Aires y el conurbano bonaerense y las relaciones amorosas y familiares. Incardona utilizó ese momento de su intervención en el blog (Días que se empujan en desorden), para forjar uno de los motivos que Roland Barthes (1986) ha señalado como funciones de los diarios de escritores: la invención de un estilo. El autor dijo que su blog documentó su "crecimiento en la escritura" (Incardona, 2011) corroborando, con el paso de los días, un proceso de cambio que se tradujo en dos series de textos, "Objetos maravillosos" y "La resistencia" que, mixturadas, dieron origen a su primer libro de relatos, titulado como la primera serie. 
La serie "Objetos maravillosos" comenzó en agosto de 2005, mientras que "La resistencia" entregó su primer texto el mes siguiente. Según el autor, las series fueron un modo de "ordenarse dentro de la velocidad de Internet"; en la primera se dedicó a cronicar su cotidianeidad en la venta de anillos artesanales y, en la segunda, a explorar el "ejercicio del diario íntimo" (aunque ambas tengan los mismos objetivos) (Incardona, 2011). Esto estructuró su interés de trabajar con lo anecdótico y con la narración de ambientes: atravesar las series es recorrer documentos que expusieron su cotidianeidad en un período determinado y explicitaron el pulido del oficio. Su producción literaria nunca se desligó de la relación presente- pasado, algo que se evidenciaba en sus posts: en "Sujetos maravillosos" (2006a) le puso nombre al orden de sus días de trabajo ambulante; en "El almacén de Juanita" (de la serie "La resistencia", [2006b]) recurría nuevamente a la memoria, el barrio y a la familia para, en palabras de Ludmer (2006), "fabricar presente": además de ofrecer una foto (se sugería el almacén en cuestión, como referencia documental), explotaba el recurso del hipervínculo ofreciendo un tejido de distintos textos del blog, todos regidos por el mismo sentido de diario. Los enlaces que se encuentran en ese relato están anclados en palabras clave: madre, Villa Celina, Tino, unos de mis cuentos, papá, casa de mis padres: al clickear se accede a otros textos, estén o no en las series. Incluso al clickear donde Incardona escribió "creí estar en uno de mis cuentos", se accede a una lista de la revista El interpretador donde figuraban todos los cuentos de Incardona publicados allí. Esto no es un mero dato descriptivo: en el centro de lo problematizado por Ludmer (2006), ese tono de diario-crónica de vida no buscaba más que concebir la creación literaria en una misma entidad con la realidad de autor.

Incardona jugó el juego de la difuminación de fronteras entre lo imaginado y lo vivido y expuso así el origen de una matriz de producción. Su crecimiento narrativo, fomentado por la articulación entre las cualidades del formato y sus intereses "de época" ("los comentarios daban una satisfacción inmediata; escribir en el blog era una forma de comunicar", afirmó Incardona [2011]), dieron como resultado su despegue literario en formato libro, con los relatos-crónicas de Objetos maravillosos (Ed. Tamarisco, 2007).

Daniel Link2, por su parte, entre muchos contenidos de carácter cultural y periodístico publicó, durante sus primeros años de blogueo en Linkillo (2003 a 2005), párrafos autorreferenciales exponiendo pensamientos, situaciones, escenas sin más motivo que el de alimentar la extimidad: mostrar el devenir de sus actividades, de su barrio, de su trabajo; narrar lo que Josefina Ludmer (2006) llamó escrituras de una realidadficción que se despliega, en su caso, tamizada por la primera persona, rozando el monólogo interior. Esa manifestación de escribir y mostrar la intimidad diaria en pequeños posts que podrían considerarse borradores se observó en numerosas entregas, de las que destaco estos ejemplos: A vuelo de pájaro, ése es nuestro barrio: una porción tranquila de la ciudad de Buenos Aires, sin la inmerecida fama de San Telmo (donde viven Laura y Martín, María y Meco, entre tantas otras personalidades de nuestra cultura), pero también sin la sombra que la violencia pone sobre otras divisiones catastrales (Constitución o, sin caer tan bajo, San Cristóbal). (...) Nuestras instituciones son sólidas, al igual que nuestro modo de vida. Yo no tengo auto, pero cuando me estaba mudando solía usar el de mi madre para transportar libros (y más libros). Dejaba el lujoso auto en la cochera de la vuelta, por consejo de Anselmo. Una noche, exhausto, me olvidé de guardar el vehículo, que quedó estacionado en la esquina, enfrente del quiosco. A la mañana encontré una ventanilla rota y el dispositivo electrónico del "estéreo" había desaparecido. Puteando, llevé el auto al garaje. La cuidadora me dijo: "Qué pena, a veces por ahorrarse cinco pesitos, después uno tiene un disgusto". Era una lección que el barrio me estaba dando. Tenemos instituciones sólidas. Conocemos perfectamente el valor del dinero. 
(...) Hoy, mientras yo dormitaba y rumiaba mi infelicidad gripal, S. fue a saludar a su abuela, que cumplía 96 años. Se encontró con un nutrido grupo de cuasi-parientes a los que no veía hacía mucho tiempo: su madrina, que vive del otro lado de "la avenida" (así se denomina a la Av. Entre Ríos en el barrio), Laura, que fue novia de su padre, acompañada de su hija (una contadora de 30 años que alguna vez lo pretendió), y que ejerció (Laura, una viuda temible) la presidencia del consejo de administración del edificio en el que vivimos.

(Link, 2005) Link generó la forma de problematizar el valor literario con sus intervenciones exaltando, desde su escritura en el blog, rasgos que a partir de pensamientos como el de Ludmer estarían obligando a concebir una nueva manera de interpretar y criticar la producción literaria en la época de la reproductibilidad digital, como el mismo Link denominó, en guiño al legado de Walter Benjamin. Y Link supo establecer esos partes diarios y reflexivos en una obra concreta, editada: los textos que nacieron en el blog como registro de una cotidianeidad fueron editados (ampliados, recortados) y conformaron en 2007 la novela Monserrat3, anclada estrictamente al devenir de su vida en el barrio. Algo interesante en relación con esos partes reflexivos fue la nota aclaratoria que escribió para esa edición en papel: "Advertencia: La mayoría de las entregas que integran esta novelita fueron publicadas previamente en Linkillo (cosas mías) en las fechas que indican en cada caso. Los hechos y personajes son ficcionales y cualquier semejanza con la realidad es mera homonimia o coincidencia" (Link, 2007).

Fotografías de escritores

Otras pruebas, partiendo de otro lenguaje: como "reconocimiento" de las plantillas, espacio donde se muestran las publicaciones en los blogs (quizás pensadas como "lienzos" que los autores pasaron a tener a disposición en su trabajo periódico, con las facilidades de publicación multimedial) algunos autores ejecutaron acercamientos a la publicación de imágenes de distintos tipos y fotografías, en general tomando el lugar de "cronistas de sí mismos", ejecutando un doble movimiento de expresión y de difusión de sus actividades cotidianas y, a su vez, explotando el espacio como archivo. Algunos autores comenzaron a publicar fotos y crónicas de los viajes que realizaban; algunos, como Daniel Link, ofrecieron secciones especiales en su blog, dedicadas al relevamiento escrito y visual de lo dicho y lo hecho.

Comienzo, no obstante, con los casos de Gustavo Nielsen4 y Pedro Mairal5. Nielsen, en primer término, también ha indagado esas prácticas con la singularidad de su trabajo como arquitecto. En su blog Milanesa con papas se pueden encontrar fotografías de sus viajes y de obras, pero no sólo relacionadas con sus proyectos literarios: se encuentran en su blog fotos sobre edificios, estructuras, imágenes de diseños y trabajos realizados; croquis y renders sobre, por ejemplo, un stand que el autor ideó para una editorial (Nielsen, 2007).

Nielsen ofreció una manera sutil de conjugar sus profesiones a partir de la imagen, algo que se comunicó también con algunas acciones que ejecutó durante un tiempo Mairal en contextos de viajes y actividades. Con la misma intención de relevar hacia la mirada de los lectores, Mairal, por una combinación entre su trayectoria precozmente exitosa, el prestigio de su obra y sus inquietudes estéticas con el trabajo de la imagen, compartió en sus blogs El señor de abajo y Pedro Mairal contenidos mixtos: prosa, fotografías y videos que nacieron de la cobertura de sus participaciones autorales. Una de las prácticas que fueron dominantes para Mairal se basó en el anuncio de viajes, lecturas o firmas de libros en congresos o eventos literarios; a los anuncios solía acompañarlos con imágenes o fotos de los sitios que visitó, o con imágenes tomadas por él mismo en los eventos. Es necesario distinguir, en su trabajo, cómo la secuencia temporal definía la publicación de fotos 
ajenas, a la manera de una gacetilla de prensa, u otras maniobras más personales y experimentales: cuando anunciaba una participación futura, publicaba fotos de las ciudades o afiches de los eventos. Cuando publicaba posts una vez sucedidos los viajes, solía mostrar fotos propias, consolidando una costumbre: la realización de collages de su autoría, armados con secuencias de fotos y hasta videos realizados con su cámara. Según afirmó en una entrevista, era una práctica que realizaba en privado, hasta que descubrió "lo lindo de mostrar el proceso" y comenzó a videograbarse armando collages de fotos (Mairal, 2011).

Explicaré esto a continuación, más como experimento narrativo que como relevamiento de imágenes.

Pero, quien mejor sistematizó este tipo de prácticas fue, como adelanté, Daniel Link. En su blog existe una etiqueta, "Diario de viajes", que terminó por reunir un enorme corpus del autor en esta línea: fotografías que tomó en viajes, que operan como crónicas informales y hasta humorísticas de sitios visitados, aspectos muy particulares de culturas distantes, además de comentarios sobre eventos a los que fue invitado (casi siempre con fotos propias) y otras crónicas en registro más cercano al periodismo. Coberturas, incluso, para el suplemento cultura del diario Perfil. El material es vasto y se remonta a los primeros momentos del blog (20032005), por lo que no es erróneo marcarlo como una línea dominante en sus contenidos: Link explotó su blog como un espacio de percepción en el que inscribe vivencias cotidianas propiciadas por su trabajo, a través de la articulación de distintos lenguajes donde las fotografías amplían el carácter descriptivo (y también argumentativo) de sus propias coberturas, o cumplen la función de "constatar" lo narrado en sus crónicas, a la manera de notas al pie, pero en imágenes.

Muchas fotografías remiten a viajes en general propiciados por su trabajo académico y crítico: Córdoba (2010a), Buenos Aires (2010b), sitios del exterior (2010c). Y la prosa que también ocupa gran parte de esa sección de su blog, y que funciona en articulación con las imágenes, afina (especifica) un modo particular de mirar y, por tanto, de narrar: crónicas que se vertebran a partir de recuerdos personales, de una suerte de ilusión de monólogo interior, que rozan el umbral difuminado entre la voz ficcional y la pretensión documental o crítica y que consolidan un ambiente en el que las fotografías contextualizan los pensamientos del autor (2010d).

\section{Experimentos narrativos a partir de la imagen}

En esa intención narrativa, los juegos o las pruebas no a la par de los contenidos audiovisuales sino a partir de ellos han marcado otro aspecto decisivo en el abanico de las disposiciones estéticas de los escritores blogueros: el "juego" de la inspiración encauzado (objetivado) en la velocidad de los posts. Varios autores han tratado a las imágenes como elementos conformadores de un relato; Mairal, como adelanté, reprodujo el movimiento de escenas particulares a partir del armado de una ilusión tridimensional, con fotos que él mismo tomaba. Mairal tomaba las fotos de un espacio y armaba, artesanalmente, un cuadro amplio que surgía poco a poco de esa manipulación: construía una perspectiva, un ambiente concreto en el que no era el único presente. Pero, además de tomar las fotos y de "encastrarlas", ejecutaba ese armado filmándose, lo que otorgaba otra capa de movimiento: construir la escena para que después la escena despliegue su contenido en el collage terminado. $Y$ todo eso lo publicaba en su blog.

Así como algunas de sus publicaciones recurrentes fueron columnas en medios gráficos a modo de pintura, de pequeña semblanza cotidiana, ésta fue otra forma que el autor ejecutó como registro paralelo a su registro más "formal", o más cercano a la escritura de ficción. Entre todas las acciones marginales a la ficción que ejecutaron 
los autores, éstas se destacaron por reproducir con sus mismas manos, y registrar con los dispositivos técnicos, una comunión de ejercicios que antes la "tradición" separaba: expresiones nacidas del lenguaje visual y no del verbal.

La imagen 1 remite a la participación de Mairal en un Encuentro de Escrituras en Uruguay, donde "cubrió" lo sucedido, y el backstage del viaje, con dos collages y algunos textos que sólo contextualizan las escenas. Se trata de una cobertura posterior a su participación, donde dejó de lado la "difusión" del evento para expandir impresiones y recuerdos, y culminó con un collage de un encuadre amplio. La imagen 2 materializa el relato del collage (Mairal, 2007): el autor se videograbó armando el collage, en el orden necesario para que cada fotografía que va armando la escena incorpore elementos al relato en una consecución de acciones característica de la escritura prosaica: la sucesión de los hechos se ofrece como sucesión de aportes a la escena. La técnica del collage es similar al ejemplo anterior, pero el registro del proceso a partir del video (también hay sonido) refuerza la potencia narrativa: el orden de la secuencia fabrica, además de la escena, la tensión de los protagonistas y del ambiente.

Patricia Suárez6, por su parte, ofreció otro ejemplo relevante en este análisis de la "inspiración" narrativa surgida de imágenes, con menos despliegue técnico pero con mayor libertad a la hora de proponer la construcción de escenas desde la ficción (la lengua desplegada).

Norma Carricaburo (2011, p. 65) ha mencionado las narraciones de Julio Cortázar y de Manuel Mujica Láinez, desde mediados del siglo pasado en adelante, como ejemplos donde las artes plásticas supieron operar como "puntos de arranque" para ciertas ficciones; la idea concreta de su análisis fue distinguir obras de artistas plásticos cuyos usos de la luz y concepciones espaciales ayudaron a los autores (dispararon en ellos) la composición de escenas, la fragmentación de la realidad o la definición de ciertos personajes.

Según Carricaburo, la función de la pintura en algunos textos de Cortázar ha sido la de "decir lo que los narradores callaban", descubriendo aspectos subyacentes a las tramas (2011, p. 65). Sin embargo, en el caso de Suárez, la intención parece haber sido la contraria: tomar la obra de un pintor (el norteamericano Edward Hopper) y narrar lo subyacente, eso que late en su estética solitaria. Suárez se dedicó en su blog Discreto encanto, entre fines de 2007 y comienzos de 2008, a elaborar una serie de ambientaciones y narraciones de diversos grados de complejidad que fue rotulando cada vez con mayor amplitud (comenzó en "monólogos" y terminó en "historias") y que surgieron a partir de cuadros de Hopper.

Fueron los rasgos inherentes al formato, a partir de la posibilidad de reunir publicaciones multimediales y de reunir, día tras día, esas publicaciones, lo que le permitió publicar una serie de textos con el mismo origen.

Suárez subtituló (primero) a estas pruebas como "breves monólogos inspirados en cuadros de Edward Hopper"; comenzó en noviembre de 2007. Luego los trató de "escenas [o historias] sobre [o inspiradas en] cuadros de Hopper". Lo interesante es que comenzó proponiendo nombres a los personajes de los cuadros (publicó cada pintura "inspiradora” junto a los textos: entre ellos "Western Motel”, “Hotel Room”, “Morning Sun") y desplegando monólogos interiores (Suárez, 2007a). Luego esa inspiración se encauzó hacia la construcción de escenas: las voces narrativas abandonaron la intimidad de la primera persona y comenzaron a desarrollar contextos, describiendo una temporalidad y un ambiente, con acciones y personajes que se fueron incorporando, en varios 
casos, a esa voz en primera. Suárez trabajó más las voces y por tanto las tramas que surgieron de las imágenes.

Luego aparecieron los diálogos entre personajes (2007b). Y en uno de los últimos textos que publicó dentro de la "serie", en enero de 2008, terminó por remitirse a la estructura de un guión (Suárez, 2008): las escenas generaron un correlato dramatúrgico, es decir, esa misma materia de la inspiración se materializó en escenas concretas con la intención (como mínimo) de ser representadas.

El caso de Suárez se ha destacado por la influencia que textos e imágenes ajenas tienen en su producción digital. Suárez partió de la percepción pictórica para luego concebir las escenas como unidades narrativas que luego permitieron crear tramas y desarrollar personajes.

Una relación asimilada, y compartida, entre autor, obra y contexto, que más allá de la influencia de los pares atendió a otros lenguajes como disparadores de las propias prácticas (Imagen 3).

Lo narrado en imágenes. Manuscritos, borradores escaneados o fotografiados

En otra variante de la convivencia de los escritores blogueros con las imágenes, Sergio Chejfec7 también mostró una asimilación de la posibilidad de publicar imágenes junto a sus textos en su espacio Parábola anterior, aunque con características más cercanas a la genética textual que a las variantes repasadas: en vez de transcribir sus textos al formato del blog (como se ve en el diseño paratextual de cada plantilla), Chejfec optó por compartir imágenes de sus borradores. Ha ofrecido una forma de presentar su escritura que ningún otro ha practicado en los blogs: publicó fotografías de un cuaderno en el que se pueden leer algunas páginas manuscritas de su novela Baroni: un viaje. Bajo el título "Baroni: un viaje (fragmentos)" ofreció imágenes escaneadas de su manuscritura: mostró la prosa en su trazo y soporte original, analógico y artesanal, e inauguró una variante en las decisiones autorales de ventilar a sus lectores parte de la intimidad del trabajo narrativo.

Chejfec no se ha caracterizado por explotar los recursos multimediales en su blog. Pero en ese sutil movimiento generó interrogantes: ¿puede pensarse este ejemplo como punto intermedio entre el trabajo con imágenes y las pruebas de textos que otros produjeron en el formato? No parece pertinente: Chejfec no escribió desde la plataforma, sino que la consideró una suerte de limbo, un sitio donde "coagular" textos (2012). Un archivo con las singularidades propias (la curiosidad) del cambio de soporte.

La digitalización de borradores es una tarea central de los estudios crítico-genéticos, que trabajan así en la administración de archivos virtuales8. En este caso Chejfec, sin solicitudes de "críticos" dedicados a su trabajo, ¿lo habrá hecho como un simple experimento, o como un mensaje a futuros genetistas? No publicó fotos aisladas, a la manera de una simple muestra: publicó tantas fotos como fueran necesarias para que los lectores pudieran leer, directamente de mano del autor, un apartado completo, con unidad de sentido, sin cortes (algo que los formatos digitales pregonaron y llevaron a la práctica casi como una religión: la de fragmentar absolutamente todo, comenzando por el texto).

En las fotos del manuscrito (Imagen 4) se observan pocas correcciones, casi no hay tachones ni sobreescrituras. Hay algunas indicaciones de estructura, indicios del esqueleto del texto. Pero rescato la primera intención: mostrar que escribe a mano, con la toma de posición que implica ese ejercicio en un contexto de inmaterialidad, 
llevando a cabo la publicación en un formato digital. El hecho de mantener un blog y de mostrar el cuaderno de escritura es todo un signo de la posición que el autor ejerce o pretende ejercer en su consideración de la virtualidad; un ejercicio coherente con su intención de experimentar una nueva forma de archivar (y por tanto, de reinventar) su trabajo, en condiciones "flotantes".

También utilizó ese recurso con la escritura de su novela Boca de lobo (Chejfec, 2008b).

Con este antecedente también creo relevante el caso de Gustavo Nielsen, que hizo recurrente la publicación de imágenes de sus cuadernos aunque sus borradores referían al dibujo y al diseño, esto es, a su trabajo como arquitecto. ¿Por qué mencionar esto al margen de la prosa? Porque Nielsen considera sus prácticas creativas dentro de un mismo universo articulado: el diseño como narración. Nielsen publicó borradores escaneados, y aunque no referían a su obra literaria daban cuenta sin embargo de su forma de concebir el proceso creativo, algo que, incluso, es observable en las explicaciones que el autor ofrecía en torno a estas imágenes (Nielsen, 2007c; 2007d). Alguna vez publicó un artículo en el suplemento Radar de Página 12 donde sentó posición: "La arquitectura es una cosa de autores”, dijo, y acudió al pensamiento creativo transversal más allá de las disciplinas: "Hoy sabemos que la actividad artística es una forma de razonamiento en la que percibir y pensar son actos que se encuentran indivisiblemente entremezclados. Una persona que pinta, escribe, compone o danza, piensa con sus sentidos" (Nielsen, 2007b).

\section{Cierre}

Fue la cultura impresa, en su desarrollo específico de productos gráficos de todos los géneros y formatos, la que desarrolló el espacio escrito articulado con la imagen. Eso no implica una novedad aquí. Pero la irrupción de las pantallas en la vida cotidiana de los sujetos, y su influencia en la cultura, generó una tensión antes desconocida en el universo de la producción cultural y literaria, aun en medio de sus luchas históricas e incesantes que siempre discuten el carácter novedoso de todo nuevo "fenómeno" en la producción de bienes simbólicos (Bourdieu, 2002). ¿Por qué atender, entonces, a este tipo de expresiones de los autores (siempre merodeando la ficción) en los formatos web? Sencillamente porque la web instituyó, en el seno social, una autopista de información, quizás el signo más concreto de la brutalidad del modelo de consumo y de la lógica del reemplazo $y$, por eso mismo, su presencia se ha enquistado en la vida cotidiana, también, como un ¿ambiente? eficaz para huir de la realidad.

Estas manifestaciones de influencias recíprocas entre imágenes y textos, entre formatos impresos y digitales, trazos y pantallas, han traducido al trabajo escriturario (en un contexto particular, vale aclararlo) algunos guiños: autores que incorporaron a sus libros maniobras deudoras del hipermedio, o surgidas de nuevas formas de percepción e intercambio.

Esas mismas maniobras parecen haberles servido para discutir, íntimamente, con esos libros que siguen siendo el objeto de la producción cultural y literaria.

Uno de los escritores pioneros en el uso de los blogs, Hernán Casciari, que además alcanzó la legitimación del campo literario (Bourdieu, 2002) a partir de su proyecto narrativo en la web9, introdujo hace unos años la categoría de "escritor orquesta" (2005) para señalar que las exigencias actuales (económicas, sociales, mediáticas) hacen que los autores tengan a cargo no sólo la producción de sus obras, sino también el diseño de 
sus publicaciones, la difusión y el marketing: el autor haciéndolo todo. Con esa premisa, que los autores recién llegados al campo de producción cultural asimilaron rápidamente, la tarea de los autores se diversificó, ofreciendo matices como los aquí compartidos. Link ya había incorporado a sus ficciones elementos de la comunicación oral a través de medios electrónicos, antes de publicar Monserrat, aunque después hizo de la complementación de formatos una rutina; Incardona o Nielsen también lo ejecutaron a su manera, el primero de modo más iniciático y transparente, el segundo reuniendo sus capacidades narrativas bajo la noción de diseño. Suárez, priorizando la experiencia perceptiva para crear escenas.

Chejfec, por su parte, propuso una experiencia de lectura que podía resultar contradictoria para los devotos del papel: al margen de los protocolos de la genética textual, su idea fue ofrecerle al lector la posibilidad de acceder a su puño y letra (la escritura en estado puro) para atestiguar el germen narrativo de sus novelas. Pero los lectores se sumergieron en esa experiencia a través de la pantalla, y dependiendo de la transmisión de datos de la web y, gracias al escaneo: leyeron de puño y letra, en un acto casi automático dentro de las rutinas de navegación, gracias a la imagen.

Todos, entonces, rodando historias con la influencia de nuevos recursos y códigos.

Si el pensamiento filosófico occidental que heredamos en torno a los primeros estudios de la "sustancia" literaria (poética), y luego algunos teóricos dedicados a las reflexiones sobre el pensamiento y la palabra (desde los románticos citados, pasando a Heidegger [1984] o las lúcidas síntesis de Mitcham [1989] hasta los estudios de Ong [1997]), concibieron a la escritura como una forma de tecnología (que, como afirmó Juan Mendoza [2011], para los griegos implicaba una mezcla de "ars" y "tekhne"), este recorrido ayuda a actualizar la mirada del artificio, en estos ambientes tan deudores de la lógica fragmentaria, donde lo que parece imperar es la idea, y la reproducción, de "bloques de sentido", de "unidades de significado". La imagen, en estos ejemplos de producción, ha formado parte de la misma jerarquía de artificio que las palabras: ésta fue quizás la prueba más desplegada, quizás la mayor expectativa en el trabajo cotidiano de algunos escritores, durante la década pasada.

Según Jacques Derrida (2005), para Sócrates la escritura se presentaba en esencia como algo artificial y técnico, frente a la naturalidad de la memoria; eso rescata para Juan Mendoza (2011) el vínculo íntimo entre escritura y tecnología10, que algunos escritores parecieron "hacer carne", quizás sin darse mucha cuenta, en estas prácticas.

¿Cómo seguir pensando ese vínculo? ¿Adónde se dirige la fragmentariedad de estos artificios técnicos? Quizás sea éste un interrogante válido para pensar el devenir de estas búsquedas expresivas que, aunque han actualizado la reflexión sobre las escrituras en prosa en algunos contextos particulares (Ludmer, 2006; Drucaroff, 2011), no terminan de afianzar las conclusiones sobre cómo seguir pensando la idea de totalidad, o de la procura de un sentido en curso, deudor de las experiencias sensibles atadas al devenir de los sujetos, al tiempo moroso del asiento de las vivencias. Será nuestra tarea seguir pensando cómo concebir estos matices en las pruebas de los autores, a partir de estos ejemplos pero sin dejar de lado los relatos y las formas de asiento reflexivo que buscan sobrevivir a la volatilidad del impacto de la luz, que se imprime en la retina y en los imaginarios pero que parece difuminarse con el vértigo superador de los dispositivos técnicos. 
1. Buenos Aires, 1971.

2. Buenos Aires, 1959.

3. El título remite al barrio porteño en el que vive el autor.

4. Buenos Aires, 1962.

5. Buenos Aires, 1970.

6. Rosario, 1969.

7. Buenos Aires, 1956.

8. Una institución prestigiosa en el desarrollo de esta disciplina es el Centre de Recherche Latino-américaines / ARCHIVOS, de la Université de Poitiers, Francia, que administra y mantiene archivos virtuales de escritores latinoamericanos.

9. http://editorialorsai.com/blog/ 10. Para explicar el cambio en el uso de los términos, de técnica a tecnología, recomiendo consultar Lo tecnológico y lo imaginario. Las nuevas tecnologías como creencias y esperanzas colectivas, de Daniel Cabrera (2006), Editorial Biblos.

Bibliografía

Aguirre Romero, J. (1997). "El futuro del libro". Facultad de Ciencias de la Información. Universidad Complutense de Madrid. Disponible en: http://www.ucm.es/info/especulo/numero5/futlibro.htm\#vnota1.

Arfuch, L. (2002). El espacio biográfico. Buenos Aires: Fondo de Cultura Económica.

Barthes, R. (1986). Lo obvio y lo obtuso. Imágenes, gestos, voces. Barcelona: Paidós.

Benjamin, W. (1987 [1935]). "La obra de arte en la época de su reproductibilidad técnica”. En Discursos interrumpidos I. Madrid: Taurus.

Bourdieu, P. (2002). Las reglas del arte. Génesis y estructura del campo literario. Barcelona: Anagrama.

Cabrera, D. (2006). Lo tecnológico y lo imaginario. Las nuevas tecnologías como creencias y esperanzas colectivas. Buenos Aires: Biblos.

Carricaburo, N. (2008). Del fonógrafo a la red. Literatura y tecnología en la Argentina. Buenos Aires: Ediciones Circeto.

Casarin, M. (2007). Vicisitudes del ensayo y la crítica. Córdoba: CEA-Alción Editora.

Casciari, H. (2005). "Un nuevo invento argentino: la blogonovela”. Diario La Nación, Buenos Aires. Disponible en: http://www.lanacion.com.ar/735046-entrevista-a-hernan-casciari. 
Chartier, R. (1994). Libros, lecturas y lectores en la Edad Moderna. Madrid: Alianza Editorial.

. (2001), “¿Muerte o transfiguración del lector?”. Edición digital. Biblioteca Virtual Miguel de

Cervantes. Alicante. Disponible en: http://bib.cervantesvirtual.com/historia/CarlosV/recurso1.shtml.

Chejfec, S. (2008a). "Baroni: un viaje (fragmentos)". En Parábola anterior. Disponible en:

http://parabolaanterior.wordpress.com/2008/05/06/baroni-un-viaje-fragmentos/.

. (2008b). "Boca de lobo (fragmentos)". En Parábola anterior. Disponible en:

http://parabolaanterior.wordpress.com/2008/05/01/boca-de-lobo-fragmentos/.

Colla, F. (2010). Escribas, monjes, filólogos, ordenadores. La preservación de la memoria escrita en Occidente. Córdoba: Alción editora.

Derrida, J. (2005 [1967]). De la gramatología. Buenos Aires: Siglo XXI.

Drucaroff, E. (2011). Los prisioneros de la torre. Política, relatos y jóvenes en la posdictadura. Buenos Aires: Emecé.

Ellul, J. (1990 [1960]), La edad de la técnica. Barcelona: Octaedro.

Fumero, A. (2005). "El abecé del universo blog”. En revista Telos 65, Madrid, octubrediciembre.

Incardona, J. (2006a). "Sujetos maravillosos". En Días que se empujan en desorden. Disponible en:

http://diasqueseempujanendesorden.blogspot.com.ar/2006/04/om-8-sujetosmaravillosos.html.

. (2006b). "El almacén de Juanita”. En Días que se empujan en desorden. Disponible en:

http://diasqueseempujanendesorden.blogspot.com.ar/2006/10/rexistencia-28-el-almacn-de-la-juanita.html.

Link, Daniel (2003). Cómo se lee y otras intervenciones críticas. Buenos Aires: Norma.

. (2005). "Círculas concéntricos". En Linkillo (cosas mías). Disponible en:

http://linkillo.blogspot.com.ar/2005/02/crculos-concntricos.html.

. (2007). Monserrat. Buenos Aires: Mansalva.

. (2010a). "Camino de ida". En Linkillo (cosas mías). Disponible en:

http://linkillo.blogspot.com.ar/2010/12/camino-de-ida.html.

. (2010b), "Paradojas". En Linkillo (cosas mías). Disponible en:

http://linkillo.blogspot.com.ar/2010/10/paradojas.html.

. (2010c), "El propio Cusco (ombligo del mundo)". En Linkillo (cosas mías).

Disponible en: http://linkillo.blogspot.com.ar/2010/12/el-propio-cusco-ombligo-delmundo.html. 

(2010d). "Amor a Roma". En Linkillo (cosas mías). Disponible en:

http://linkillo.blogspot.com.ar/2010/09/amor-roma.html.

Ludmer, J. (2006). "Literaturas posautónomas". Ciberletras. Revista de crítica literaria y de cultura. Diciembre. Disponible en: http://www.lehman.edu/ciberletras/v17/ludmer.htm.

Mairal, P. (2007). “Una cerveza” [captura de pantalla]. El señor de abajo. Disponible en: http://elseniordeabajo.blogspot.com.ar/2007/02/cerveza.html. (2009), "Maldonado" [captura de pantalla]. Pedro Mairal. Disponible en: http://pedromairal.blogspot.com.ar/2009/09/maldonado.html.

Mendoza, J. (2011). El canon digital. La Plata: La Crujía Ediciones.

Mitcham, C. (1989). ¿Qué es la filosofía de la tecnología? Barcelona: Anthropos.

Mumford, L. (1961). Arte y técnica. Buenos Aires: Nueva Visión.

Nielsen, G. (2007a). "Mis dibus”. En Milanesa con papas. Disponible en: http://milanesaconpapas.blogspot.com.ar/2007/08/mis-dibus.html]. (2007b). "Mil ideas". En suplemento Radar, Diario Página 12, 2 de septiembre. Buenos Aires. Disponible en:http://www.pagina12.com.ar/diario/suplementos/radar/9-4073-2007-09-03.html]. . (2007c). "Dos dibus más de mis cuadernos". ". En Milanesa con papas. Disponible en: http://milanesaconpapas.blogspot.com.ar/2007/08/dos-dibus-ms-de-miscuadernos.html. . (2007d). "Y los últimos dos". En Milanesa con papas. Disponible en: http://milanesaconpapas.blogspot.com.ar/2007/08/y-los-ltimos-dos.html.

Ong, W. (1997). Oralidad y escritura. Buenos Aires: Fondo de Cultura Económica.

Orihuela, J. (2004). “Los weblogs: revolución y consolidación”. Revista Latinoamericana de Comunicación Chasqui n085, marzo. Centro Internacional de Estudios Superiores de Comunicación para América Latina. Quito, Ecuador. Disponible en: http://redalyc.uaemex.mx/src/inicio/ArtPdfRed.jsp?iCve=16008505.

Rapport Du Libre Numérique (2008). Ministère de la Culture et de la communication.

Département de l'information et de la communication. Francia. Disponible en: http://www.culture.gouv.fr/culture/actualites/conferen/albanel/rapportpatino.pdf].

Schmucler, H. (1997). Memoria de la comunicación. Buenos Aires: Biblos.

Suárez, P. (2007a). "Morning Sun, 1952. Breves Monólogos inspirados en cuadros de Edward Hopper”. En Discreto encanto. Disponible en: http://discretoencanto.blogspot.com.ar/2007/11/morning-sun-1952-brevesmonlogos.html. 

(2007b). “Western Hotel, 1957. Historias inspiradas en Hopper”. En Discreto encanto. Disponible en: http://discretoencanto.blogspot.com.ar/2007/12/western-motel-1957-historias-inspiradas.html.

(2008). "Reunión por la noche, 1949. Sobre una imagen de Edward Hopper". En Discreto encanto. Disponible en: http://discretoencanto.blogspot.com.ar/2008/10/reunin-por-la-noche-1949-sobre-una.html].

Wrede, O. (2005). "Are blogs different to forums?" Disponible en: http://wrede.interfacedesign.org/archives/992.html.

Blogs citados

Juan Diego Incardona. www.diasqueseempujanendesorden.blogspot.com Daniel Link. www.linkillo.blogspot.com Pedro Mairal. www.elseniordeabajo.blogspot.com Gustavo Nielsen. www.milanesaconpapas.blogspot.com Patricia Suárez. www.discretoencanto.blogspot.com Sergio Chejfec. www.parabolaanterior.wordpress.com Abstract:

The relationships between the written production and virtual universe that emerge from the popularization of digital formats led to think about a phenomenon that expanded the tensions between print culture and digital culture. In the context of "technological explosion," the weblog was incorporated by writers to explore new facets of work and linking.

In this paper I work with one facet developed by writers: the mixture between text, image, sound and audio, even if that crossing had not been conceived before as "everyday" routines of publications, regardless if they were fictional or marginal texts. The analysis of writers' blogs has been a further example of the brand of an era: voices that were actually screen text and therefore the word that was and is translated into an image. The images are part of the authors' texts, their plots, their plans, and the experimentation between verbal and visual language. It becomes ever more evident in their crosses and mutual influences.

Key words:

writers' blogs - printed culture - digital culture - written production - hypermedial environment.

Resumo:

As relações entre a produção escrita e o universo virtual que surgiram da popularização dos suportes e formatos digitais desencadearam na aparição de certos fenômenos que ampliaram as tensões entre a cultura impressa e a chamada cultura digital. No contexto de a explosão informática, o formato do blog foi adotado por escritores a fim de explorar novas facetas de trabalho e vinculação de ideias.

Aqui trabalho com uma das facetas que foram desenvolvidas: a mistura entre texto, imagem, som e áudio no trabalho, mesmo que esse cruzamento não tenha sido concebido antes como algo cotidiano nas publicações diárias, já em casos de textos de ficção ou literatura marginal. A análise de blogs de escritores tem significado um exemplo significativo da marca de época: vozes que foram, na verdade, texto no monitor e, portanto, a palavra que foi e é traduzida em imagem. Estas imagens fazem parte dos textos de autores, de suas tramas, 
seus planos, e o desenvolvimento da experimentação entre as linguagens verbal e audiovisual aparece cada vez mais em seus cruzamentos e influências.

Palavras chave: blogs de escritores - cultura impressa - cultura digital - vídeos - produção escrita - ambiente hipermedial.

Lo narrado en imágenes (o las imágenes narradas). Ficciones, pruebas, trazos y fotografías en las publicaciones de los escritores en blogs fue publicado de la página 17 a página34 en Cuadernos del Centro de Estudios de Diseño y Comunicación № 61 